\title{
Management of choroidal metastasis using external beam radiotherapy: a retrospective study and review of the literature
}

\author{
Zakaria Ahmed Youbi, Enachescu Ciprian, Caraivan Ionela, Bennani Zineb, Khounigere Majdouline, Kotzki Léa, \\ Pialat Pierre-Marie, Sesques Pierre, Yossi Séna
}

Department of Radiation Therapy, South Lyon Hospital, 69495 Lyon, France.

Correspondence to: Dr. Zakaria Ahmed Youbi, Department of Radiation Therapy, South Lyon Hospital, 165 Chemin du Grand Revoyet, Pierre Benite, 69495 Lyon, France. E-mail: zakaria.youbi@gmail.com

How to cite this article: Youbi ZA, Ciprian E, Ionela C, Zineb B, Majdouline K, Léa K, Pierre-Marie P, Pierre S, Séna Y. Management of choroidal metastasis using external beam radiotherapy: a retrospective study and review of the literature. J Cancer Metastasis Treat 2017;3:105-10.

Article history:

Received: 11-01-2017

Accepted: 23-03-2017

Published: 30-06-2017

Key words:

Radiotherapy,

choroid,

metastasis,

ocular,

tumors,

visual,

acuity

\begin{abstract}
\end{abstract}
\section{INTRODUCTION}

Choroidal metastases are rare in the development of solid cancers that can affect the visual prognosis of the patient in the short to medium term. In several autopsy series, they have an incidence of $4 \%$ to $12 \%$ in patients with solid tumors. ${ }^{[1,2]}$ The uveal tract is the most common site of intraocular 
metastases, probably due to anatomical reasons and blood vessel supply. ${ }^{[3]}$ The treatment of these tumor localizations is not yet standardized but is based mostly on external radiotherapy, which with its sophisticated new techniques allows better results while protecting healthy organs around. ${ }^{[4,5]}$ We conducted a retrospective study and synthesis of the literature to determine the interest of radiotherapy in the management of choroidal metastases.

\section{METHODS}

\section{Patient characteristics}

We reviewed the cases of 28 patients treated in our center in the period between August 1996 to June 2015 and presenting choroidal metastases in a context of solid cancer, excluding melanomas. All information regarding the date and site of the primary tumor, status of the primary at the time when choroidal metastasis was diagnosed, date of choroidal metastatsis diagnosis, symptoms, localization and number of lesions in the eye, radiation treatment and technical parameters was collected. All the ophthalmological examinations were done in the ophthalmology department of our center, and then sent to our department for oncological management by radiotherapy [Table 1].

\section{Radiotherapy}

For each patient, excluding those treated in twodimensional radiotherapy (2D), a scanner with a slice thickness of $2.5 \mathrm{~mm}$ was performed in treatment position using a thermoformed contention mask to maintain a reproducible position throughout the treatment. Treatment plan was performed using the ECLIPSE TM treatment planning system (VARIAN ${ }^{\circledR}$, Palo Alto, CA, USA). The treatment was delivered with a VARIAN CLINAC ${ }^{\circledR}$ Linear Accelerator. The doses varied from $20 \mathrm{~Gy}$ to $50 \mathrm{~Gy}$ with a fractionation of $3 \mathrm{~Gy}$ to $5 \mathrm{~Gy}$ in two-dimensional $2 \mathrm{D}(n=5)$, conformational $3 \mathrm{D}(n=21)$, intensity modulation $(n=2)$. The most used prescription regimen consisted of delivering $30 \mathrm{~Gy}$ into 10 fractions of $3 \mathrm{~Gy}(n=18)$. The clinical target

Table 1: Clinical characteristics

\begin{tabular}{lc}
\hline Characteristics & Effective \\
\hline Gender & 9 \\
Man & 19 \\
Women & 58 years (34-75 years) \\
Medianage & 9 \\
Primary tumor localization & 15 \\
Lung & 1 \\
Breast & 1 \\
Ovarian & 1 \\
Kidney & 1 \\
Prostate & \\
Tnknown primitive & 13 \\
Localized & 15 \\
Metastatic & \\
\hline
\end{tabular}

volume CTV was the posterior uvea-choroid of the eye. The planning target volume PTV represented CTV with a margin varying between $0.5 \mathrm{~cm}$ and $1 \mathrm{~cm}$. The use of magnetic resonance imaging (MRI) and merge it with the dosimetric scanner could help delineating the target volume with precision for a better planning of the treatment plan which will make it possible to give a large dose to the target volume to be treated (choroid) and sparing the risky organs beside it [Table 2].

\section{Statistical analysis}

SAS $^{\circledR}$ JMP 11 software (SAS Institute Inc. Cary, NC, USA) was used for statistical analysis. An overall description of the population was carried out. For qualitative data, numbers and percentages were calculated. Quantitative data, median or mean by normality, as well as extreme values with minimum and maximum were estimated. Fisher's exact test was used to determine the association between two qualitative variables with a significance level $P<0.05$.

\section{RESULTS}

Patients had cancer of breast $(n=15)$, lung $(n=9)$, ovarian $(n=1)$, kidney $(n=1)$, prostate $(n=1)$, with an unknown primitive at the moment of the diagnosis $(n=1)$. The median age was 58 years [extreme $(E)$ : 34 to 71 years]. Our cohort contained 19 women and 9 men (sex ratio $=0.47$ ). The tumor stage before the discovery of choroidal metastases was metastatic for $48 \%$ of the patients. Eye involvement was unilateral

Table 2: Results of external beam radiotherapy in our cohort

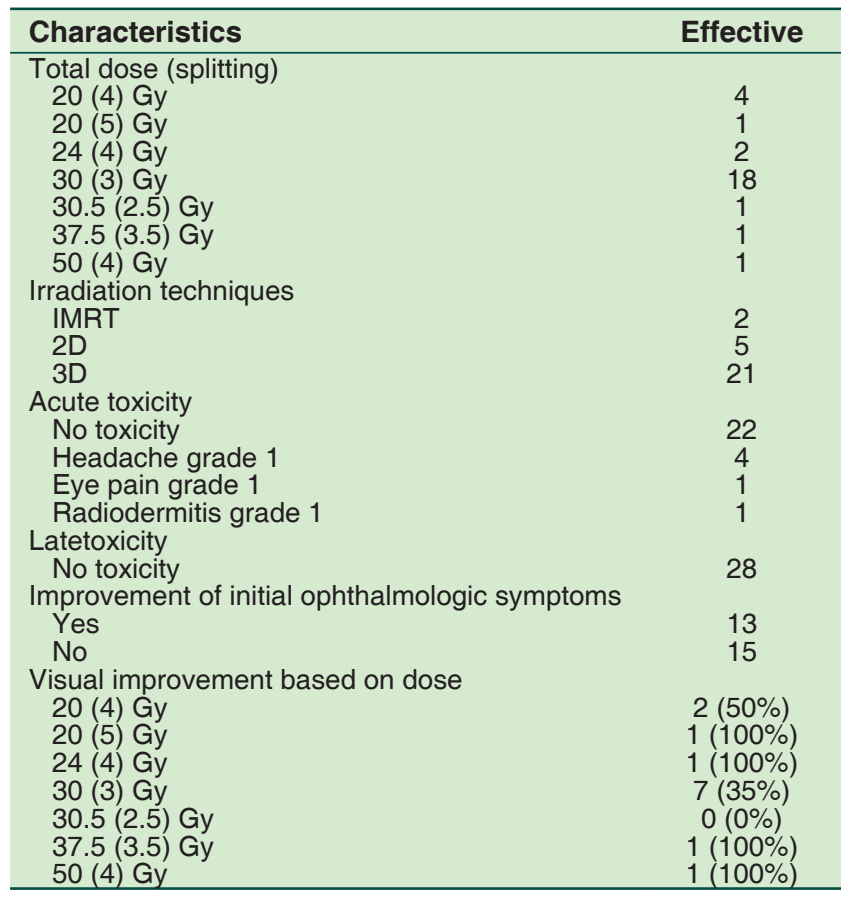


( $n=22$ ) or bilateral $(n=6)$. The inaugural symptoms were variable: decreased visual acuity, visual field amputation with scotoma, photophobia, myodesopsia [Table 2].

At the end of the irradiation, 13 patients (46\%) showed an improvement in ophthalmologic symptoms. For the others, a stabilization of the symptoms was noted $(n=15)$. No patients showed visual degradation. No acute or late grade 2-3 toxicity was objectived. The histological type was not significantly correlated with the response $(P=0.5)$ according to Fisher's exact test. Furthermore, there was no dose-response relationship in our serie. The response rates following delivered dose are shown in Table 2.

\section{DISCUSSION}

Choroidal metastases are frequently pauci symptomatic with unspecific visual signs (scotoma, myodesopsis, photophobia, ocular pain) or even strictly asymptomatic. ${ }^{[5-8]}$ The exact prevalence of this tumor localization is not known with certainty and can be very variable depending on the size of metastatic patients cohorts. The median age at diagnosis in the main published series ${ }^{[6,7]}$ is 55 years with a median time between diagnosis of primary cancer and choroidal metastasis of 49-month. ${ }^{[5]}$ Primary tumors are predominantly of mammary and pulmonary origin. ${ }^{[6,7]}$ In several series, women are predominantly involved. These data are consistent with the results of our study. However, others tumor localizations are providers of choroidal metastases such as thyroid, kidney, prostate, esophagus or melanoma cancers. ${ }^{[7,8]}$ In some cases, ocular involvement may be symptomatic in one eye and remain completely asymptomatic on the other, raison why patients should systematically benefit from a complete specialized ophthalmologic examination, prior to the initiation of a treatment. According to some authors, bilateral involvement is associated with a shorter likelihood of survival. ${ }^{[9]}$ On ophtalmoscopy, choroidal metastases appear as flat orange lesions located most often at the posterior pole of the eye, which can induce focal retinal detachment. Anterior or posterior uveitis may sometimes be associated. Mode A (Amplitude) and B (Brightness) ultrasound as well as fluorescein angiography can assist in diagnosis. They can demonstrate hyperfluorescence at the late time (venous) and hypofluorescence at the early (arterial). ${ }^{10,11]}$ The diagnosis of certainty by biopsy puncture is rarely obtained given the potential complications. It is based on clinico-radiological arguments and the clinical context (patient with metastatic solid cancer). On scan (CT), choroidal tumors appear as hyperdense heterogeneous lesions enhanced by the contrast medium. MRI is not essential for diagnosis but may be of interest in target volumes delineation for radiotherapy. ${ }^{[12]}$ The choroidal tumors appear as heterogeneous masses with hyper signal T1 and hypo signal T2 which can be enhanced with the injection of Gadolinium.

The main therapeutic option is external radiotherapy. A thermoformed mask is generally used in order to ensure reproducibility of the treatment. As discussed in the prospective study on the radiotherapy of choroidal metastases, the anatomo-clinical target volume, which is the choroid, can be treated via one or two direct beams of 6 Megavolt energy photons. ${ }^{[13]} A$ beam angulation of $5^{0}$ to $10^{\circ}$ can be performed in order to spare the contralateral choroid. ${ }^{[14]}$ Another irradiation ballistics is possible by the use of 3 beams (anterior, posterior,

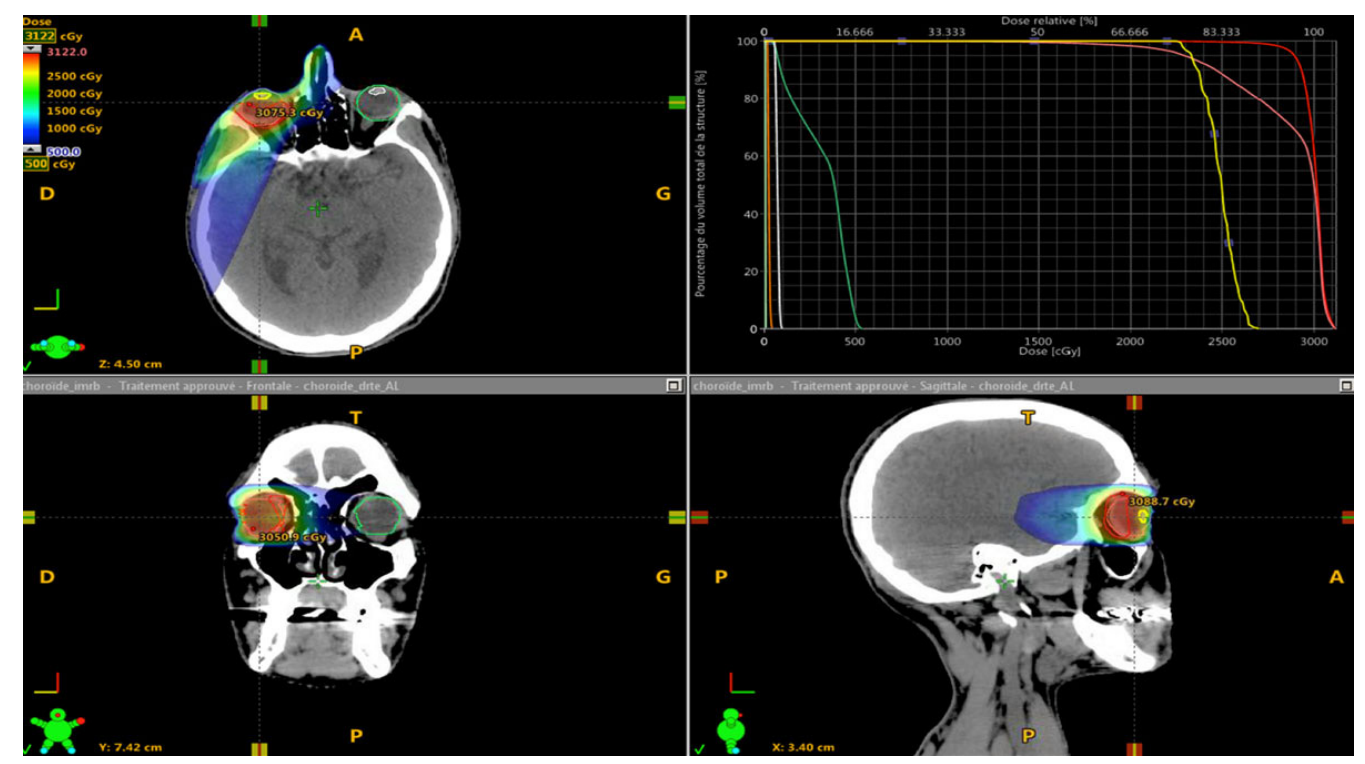

Figure 1: Intensity modulated radiotherapy using 3 beams of $6 \mathrm{MV}$ photons 
lateral). In our series, some patients benefited from an intensity modulation radiation therapy in arctherapy or static [Figures 1-3]. The contralateral choroidal sparing is controversial. It should be noted that the rate of recurrence in the untreated contralateral choroid is estimated to be low (less than 10\%). ${ }^{[15]}$ However, some authors have reported a rate between $15 \%$ and $20 \%{ }^{[16,17]}$ whereas it was zero in the German prospective trial ARO 95-08.

Potential acute side effects include radiodermatitis, focal alopecia, conjunctivitis, xerophthalmia, the severity of which is doseand field-dependent. ${ }^{[18]}$ Potential late side effects include cataract, glaucoma, keratitis, dry eye syndrome, radiation-induced retinopathy depending on the technique, dose and especially the clinical context including the patient's life expectancy. ${ }^{[19]}$ In the German prospective trial of Wiegel et al.,"20] The authors delivered a dose of $40 \mathrm{~Gy}$ in 20 fractions of $2 \mathrm{~Gy}$ and noted improvement or stabilization of symptoms in $86 \%$ of cases (an improvement in $50 \%$ and stabilization in $36 \%$ of cases). The best functional results were obtained for patients with breast cancer probably due to the use of chemotherapy after irradiation. Rosset et al. ${ }^{[21]}$ suggest a normofractionnated dose of at least $35 \mathrm{~Gy}$. However, in practice, hypofractionnated regimens are preferred in routine clinical practice. In fact, they allow

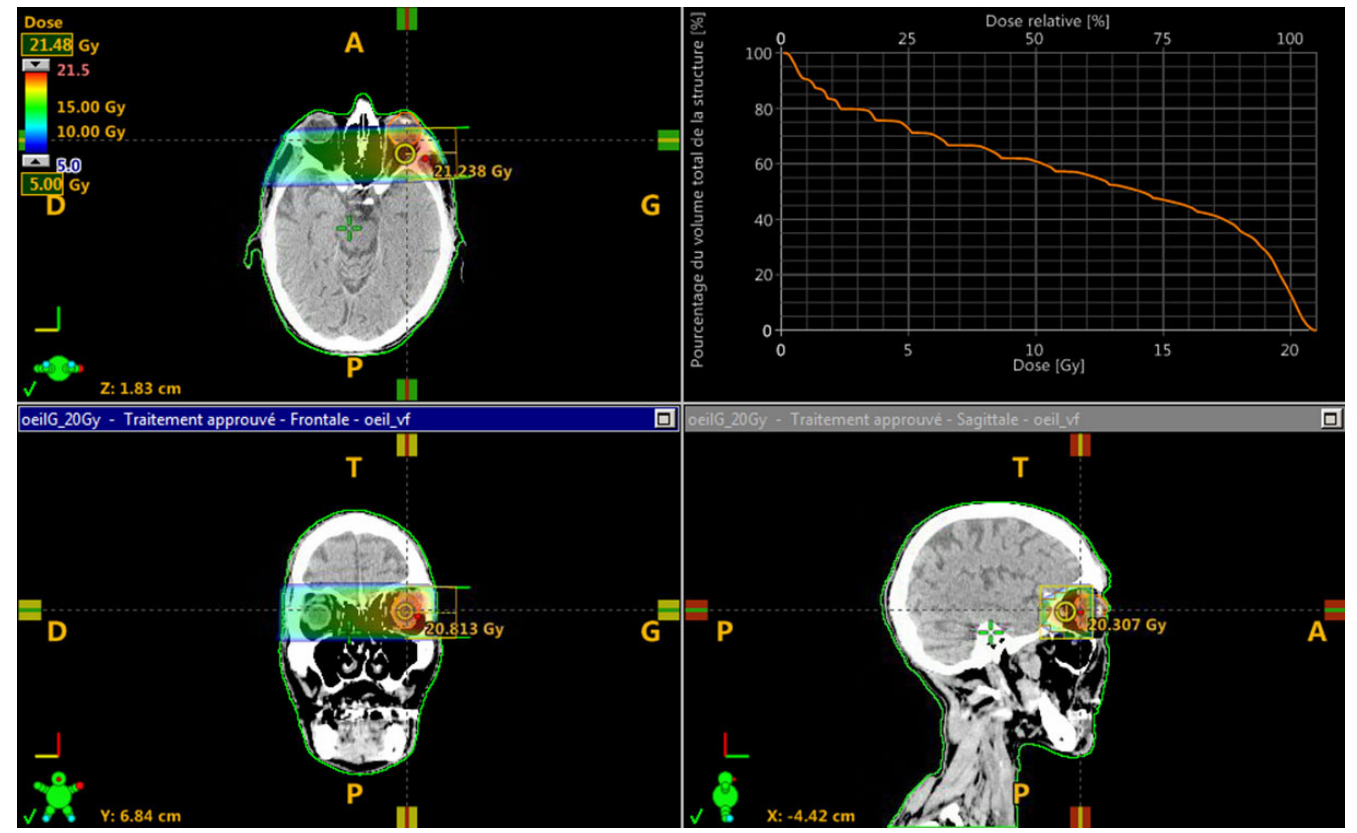

Figure 2: Conformal radiotherapy using two beams of $6 \mathrm{MV}$ photons

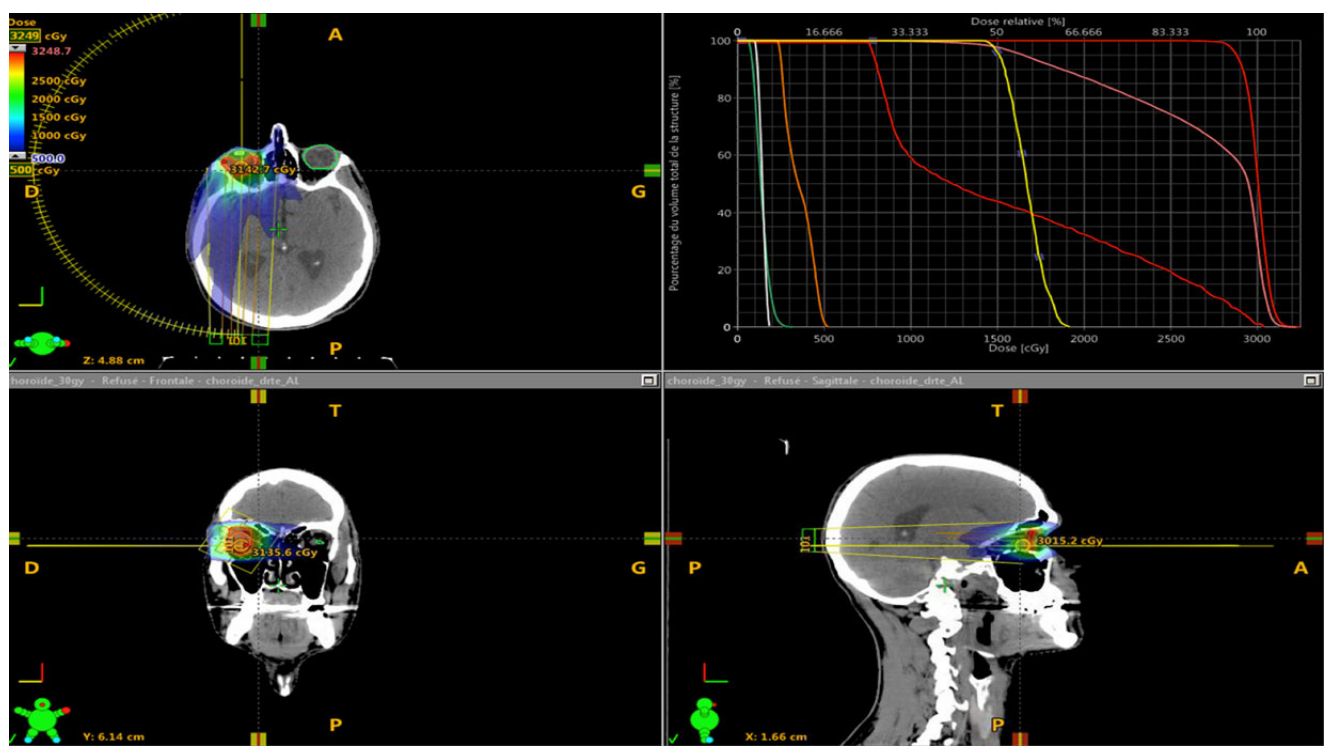

Figure 3: Volumetric modulated arctherapy using $6 \mathrm{MV}$ photons 
the patient to be treated quickly and, if necessary, reduce the time before resumption of any systemic treatment. The results of exclusive photon radiation therapy of the main cohorts published in the literature are reported in Table 3. According to the series, ${ }^{[21]}$ the rates of stabilization or improvement of symptoms vary from $57 \%$ to $100 \%$. The results of our study are comparable.

Other therapeutic alternatives to conventional photon radiation therapy have been reported. Some teams have used stereotactic radiotherapy or proton therapy on series of patients with very limited numbers. ${ }^{[22,23]}$ The results functional results obtained do not appear to be superior in terms of local control of the disease compared to photonic radiotherapy for classical tumor sites (breast, lung). These techniques should be reserved for the most radioresistant tumors including melanomas. ${ }^{[24-26]}$

Other local treatments such as plate brachytherapy, dynamic phototherapy, laser or anti-angiogenic instillations are possible but external radiotherapy remains the oldest and proven technique in clinical routine. ${ }^{[27,28]}$

In addition, systemic treatment alone with conventional chemotherapy or targeted therapy may have a local anti-tumor action on choroidal metastases. ${ }^{[29]}$ The optimal therapeutic attitude could be the sequential association of choroidal radiotherapy and systemic treatment. ${ }^{[30,31]}$

In conclusion, radiotherapy is an effective treatment and low toxicity for the management of choroidal metastases. The hypofractionated regimens should be preferred in order to reduce the delay before the resumption of a possible systemic treatment which could also have a locoregional action on the choroidal metastases. This treatment fits perfectly into the palliative or curative management of oligo- or polymetastatic disease.

Table 3: Results of external beam radiotherapy with photons

\begin{tabular}{|c|c|c|c|c|}
\hline Authors & Effective & Primitif tumor (effective) & Doses (spliting) & $\begin{array}{l}\text { Visual stabilisation or } \\
\text { improvement }\end{array}$ \\
\hline Burmeister et al. ${ }^{[23]}$ & 6 & Breast (6) & 21 to 27 Gy (3 to 3.4 Gy) & $100 \%$ \\
\hline \multirow[t]{2}{*}{ Ratanatharathorn et al..$^{[12]}$} & 19 & Breast (19) & 26 to 46 Gy ( 1.61 to 3 Gy) & $100 \%$ \\
\hline & & Breast (14) & & \\
\hline \multirow[t]{3}{*}{ Nylén et al. ${ }^{[24]}$} & 17 & Lung (1) & 20 to 45 Gy (2 to 4 Gy) & $81 \%$ \\
\hline & & Others (2) & & \\
\hline & & Lung (100) & & \\
\hline \multirow[t]{3}{*}{ Röttinger et al. ${ }^{[11]}$} & 188 & Breast (44) & 30 to 40 Gy (2 to 3 Gy) & $57 \%$ \\
\hline & & Others (44) & & \\
\hline & & Breast (38) & & \\
\hline \multirow[t]{3}{*}{ Rosset et al. ${ }^{[21]}$} & 58 & Lung (10) & 20 to 53 Gy (1.8 to 2 Gy) & $81 \%$ \\
\hline & & Others (10) & & \\
\hline & & Breast (31) & & \\
\hline \multirow[t]{3}{*}{ Wiegel et al. ${ }^{[20]}$} & 50 & Lung (13) & 40 Gy (2 Gy) & $86 \%$ \\
\hline & & Others (6) & & \\
\hline & & Breast (88) & & \\
\hline \multirow[t]{2}{*}{ d'Abbadie et al. ${ }^{[16]}$} & 123 & Lung (11) & 18 to 30 Gy (3 to 6 Gy) & $68 \%$ \\
\hline & & Others (24) & & \\
\hline \multirow[t]{2}{*}{ Demirci et al..$^{[15]}$} & 129 & Breast (129) & 20 to 64 Gy (1.5 to 3 Gy) & $82 \%$ \\
\hline & & Breast (11) & & \\
\hline \multirow[t]{3}{*}{ Bajcsay et al. ${ }^{[25]}$} & 17 & Lung (4) & 42 to 51 Gy (np) & $100 \%$ \\
\hline & & Others (2) & & \\
\hline & & Lung (3) & 30 Gy (3 Gy) or 20 Gy & \\
\hline \multirow[t]{2}{*}{ Bellmann et al. ${ }^{[13]}$} & 10 & Breast (3) & & $100 \%$ \\
\hline & & Others (4) & SBRT (20 Gy) & \\
\hline Amichetti et al..$^{[14]}$ & 49 & Breast (49) & 16 to 60 Gy (1.8 to 3 Gy) & $88 \%$ \\
\hline \multirow[t]{2}{*}{ Kreusel et al. ${ }^{[10]}$} & 18 & Lung (18) & Unspecified & $83 \%$ \\
\hline & & Breast (41) & & \\
\hline \multirow[t]{2}{*}{ Konstantinidis et al. ${ }^{[22]}$} & 96 & Lung (27) & Unspecified & $94.30 \%$ \\
\hline & & Others (28) & & \\
\hline
\end{tabular}




\section{Authors' contributions}

All authors have contributed to the realization of this work.

\section{Financial support and sponsorship \\ None.}

\section{Conflicts of interest}

There are no conflicts of interest.

\section{Patient consent}

The patient consent was obtained from the patients.

\section{Ethics approval}

Ethics approval was obtained prior to the commencement of the study.

\section{REFERENCES}

1. Bloch RS, Gartner S. The incidence of ocular metastatic carcinoma. Arch Ophthalmol 1971;85:673-5.

2. Nelson CC, Hertzberg BS, Klintworth GK. A histopathologic study of 716 unselected eyes in patients with cancer at the time of death. Am J Ophthalmol 1983;95:788-93.

3. Wiegel T, Kreusel KM, Bornfeld N, Bottke D, Stange M, Foerster MH, Hinkelbein W. Frequency of asymptomatic choroidal metastasis in patients with disseminated breast cancer: results of a prospective screening programme. Br J Ophthalmol 1998;82:1159-61.

4. Barak A, Neudorfer M, Heilweil G, Merimsky O, Lowenstein A, Inbar M, Yaal-Hahoshen N. Decreased prevalence of asymptomatic choroidal metastasis in disseminated breast and lung cancer: argument against screening. Br J Ophthalmol 2007;91:74-5.

5. Jardel P, Sauerwein W, Olivier T, Bensoussan E, Maschi C, Lanza F, Mosci C, Gastaud L, Angellier G, Marcy PY, Herault J, Caujolle JP, Dendale R, Thariat J. Management of choroidal metastases. Cancer Treat Rev 2014;40:1119-28.

6. Kreusel KM, Bechrakis NE, Wiegel T, Krause L, Foerster MH. Incidence and clinical characteristics of symptomatic choroidal metastasis from lung cancer. Acta Ophthalmol 2008;86:515-9.

7. Bajcsay A, Kontra G, Récsán Z, Tóth J, Fodor J. Lens-sparing external beam radiotherapy of intraocular metastases: our experiences with twenty four eyes. Neoplasma 2003;50:459-64.

8. Mewis L, Young SE. Breast carcinoma metastatic to the choroid. Analysis of 67 patients. Ophthalmology 1982;89:147-51.

9. Maor M, Chan RC, Young SE. Radiotherapy of choroidal metastases: breast cancer as primary site. Cancer 1977;40:2081-6.

10. Rudoler SB, Corn BW, Shields CL, De Potter P, Hyslop T, Shields JA, Curran WJ Jr. External beam irradiation for choroid metastases: identification of factors predisposing to long-term sequelae. Int J Rad Oncol Biol Phys 1997;38:251-6.

11. Röttinger EM, Heckemann R, Scherer E, Vogel M, MeyerSchwickerath G. Radiation therapy of choroidal metastases from breast cancer. Albrecht Von Graefes Arch Klin Exp Ophthalmol 1976;200:243-50.

12. Ratanatharathorn V, Powers WE, Grimm J, Steverson N, Han I, Ahmad $\mathrm{K}$, Lattin PB. Eye metastasis from carcinoma of the breast: diagnosis, radiation treatment and results. Cancer Treat Rev 1991;18:261-76.

13. Bellmann C, Fuss M, Holz FG, Debus J, Rohrschneider K, Völcker HE, Wannenmacher M. Stereotactic radiation therapy for malignant choroidal tumors: preliminary, short-term results. Ophthalmology 2000;107:358-65.

14. Amichetti M, Caffo O, Minatel E, Roncadin M, Valli MC, Lozza L, Panizzoni G. Ocular metastases from breast carcinoma: a multicentric retrospective study. Oncol Rep 2000;7:761-5.

15. Demirci H, Shields CL, Chao AN, Shields JA. Uveal metastasis from breast cancer in 264 patients. Am J Ophthalmol 2003;136:264-71.

16. d'Abbadie I, Arriagada R, Spielmann M, Lê MG. Choroid metastases: clinical features and treatments in 123 patients. Cancer 2003;98:1232-8

17. Amer R, Pe'er J, Chowers I, Anteby I. Treatment options in the management of choroidal metastases. Ophthalmologica 2004;218:372-7

18. Tsina EK, Lane AM, Zacks DN, Munzenrider JE, Collier JM, Gragoudas ES. Treatment of metastatic tumors of the choroid with proton beam irradiation. Ophthalmology 2005;112:337-43.

19. Shah SU, Mashayekhi A, Shields CL, Walia HS, Hubbard GB 3rd, Zhang J, Shields JA. Uveal metastasis from lung cancer: clinical features, treatment, and outcome in 194 patients. Ophthalmology 2014;121:352-7.

20. Wiegel T, Bottke D, Kreusel KM, Schmidt S, Bornfeld N, Foerster MH, Hinkelbein W; German Cancer Society. External beam radiotherapy of choroidal metastases -- final results of a prospective study of the German Cancer Society (ARO 95-08). Radiother Oncol 2002;64:13-8.

21. Rosset A, Zografos L, Coucke P, Monney M, Mirimanoff RO. Radiotherapy of choroidal metastases. Radiother Oncol 1998;46:263-8.

22. Konstantinidis L, Rospond-Kubiak I, Zeolite I, Heimann H Groenewald C, Coupland SE, Damato B. Management of patients with uveal metastases at the Liverpool Ocular Oncology Centre. $\mathrm{Br} J$ Ophthalmol 2014;98:92-8.

23. Burmeister BH, Benjamin CS, Childs WJ. The management of metastases to eye and orbit from carcinoma of the breast. Aust $N Z J$ Ophthalmol 1990;18:187-90.

24. Nylén U, Kock E, Lax I, Lundell G, af Trampe E, Wilking N. Standardized precision radiotherapy in choroidal metastases. Acta Oncol 1994;33:65-8.

25. Bajcsay A, Kontra G, Récsán Z, Tóth J, Fodor J. Lens-sparing external beam radiotherapy of intraocular metastases: our experiences with twenty four eyes. Neoplasma 2003;50:459-64.

26. Yang CJ, Tsai YM, Tsai MJ, Chang HL, Huang MS. The effect of chemotherapy with cisplatin and pemetrexed for choroidal metastasis of non-squamous cell carcinoma. Cancer Chemother Pharmacol 2014;73:199-205.

27. Singh N, Kulkarni P, Aggarwal AN, Rai Mittal B, Gupta N, Behera D Gupta A. Choroidal metastasis as a presenting manifestation of lung cancer: a report of 3 cases and systematic review of the literature. Medicine (Baltimore) 2012;91:179-94.

28. Inoue $\mathrm{M}$, Watanabe $\mathrm{Y}$, Yamane $\mathrm{S}$, Kobayashi S, Arakawa A, Tsukahara T, Kaneko T, Kadonosono K. Choroidal metastasis with adenocarcinoma of the lung treated with gefitinib. Eur J Ophthalmol 2010;20:963-5.

29. Fujiu K, Kobayashi N, Miyamoto H, Suzuki H. A case of choroidal metastasis of lung cancer successfully treated with erlotinib. Gan To Kagaku Ryoho 2012;39:269-71.

30. Rao RC, Gragoudas ES. Choroidal metastases from EML4ALK-positive non small cell lung adenocarcinoma. J Clin Oncol 2015;33:e112-4.

31. Barry AS, Bacin F, Kodjikian L, Benbouzid F, Balmitgere T, Grange JD. Choroidal metastases of lung neoplasm treated with external radiotherapy and polychemotherapy: a study of four clinical cases. $J$ Fr Ophtalmol 2012;35:122.e1-8. (in French) 